\title{
JONITES OCH NIMROD I JERAHME'ELS HEBREISKA KRÖNIKA
}

\author{
WITOLD WITAKOWSKI \\ Uppsala \\ $-\infty-$
}

A B STRACT The medieval Hebrew Chronicle of Yerahme'el contains a story of the meeting of Nimrod and Yonites, the (fourth) son of Noah, attributed to Strabo of Cyprus. Yonites is unknown in Jewish tradition, but can be found in a similar context as in Yerahme'el in Syriac Christian literature - for the first time in the Cave of Treasures ( 5 th cent.). Yerahme'el could not however know the Cave, and therefore one has to look for intermediary stages. One of them is the Syriac Apocalypse of Pseudo-Methodios (the end of the $7 \mathrm{th}$ cent.) directed against the Muslims, which became very popular among the Syrians and was soon translated into Greek and Latin. The Latin translation was used by Petrus Comestor (d. 1179) in his Historia Scholastica. Since its author lived in Troyes in northern France where contacts are attested between Christian and Jewish exegetes in the 12th cent., one may assume that Yerahme'el's work came into being in this region and epoch.

Den hebreiska medeltida historiografin har under senaste decennier, i motsats till vad som var fallet i början av seklet, knappast varit ett särskilt uppmärksammat forskningsämne. Jerahme’els [Yarabmə’el] krönika är inget undantag, men t.o.m. i jämförelse med andra hebreiska medeltida krönikor - korstågskrönikor, och i ännu högre utsträckning Josippon, ${ }^{1}$ som genremässigt ligger mycket nära Jerahme'els krönika - är den sistnämnda relativt okänd. Man kan exempelvis inte finna den $\mathrm{i}$ en nyligen publicerad förteckning över hebreiska medeltida historiografiska verk. ${ }^{2}$ 
Man måste först konstatera att det, med undantag för vissa fragment, inte finns någon utgåva av Krönikan, inte bara en kritisk sådan utan överhuvudtaget. Krönikan är känd endast genom en engelsk översättning som 1899 publicerades av Moses Gaster. Det är också från honom som dess titel härstammar: The Chronicles of Jerabmeel; or the Hebrew Bible Historiale, being a collection of apocryphal and pseudo-epigraphical books dealing with the history of the world from the creation to the death of Judas Maccabeus. ${ }^{3}$

Bara en handskrift av Jerahme’els krönika är känd. Den befinner sig i Bodleian Library i Oxford, härstammar från I400-talet och består av 388 blad. ${ }^{4}$ Skriven med den gamla tyska rabbinska skriften, är den med sina mycket små bokstäver inte lätt att läsa. Handskriften innehåller egentligen ett annat verk, Memoarboken (Sefer ha-Zikhronot) av Eleazar ben Asher ha-Levi. ${ }^{5}$ Denne presenterar sig som en kompilator genom att säga om sitt material "... and as I found, so I copied, and I have deftly woven the materials to form one book..."6 Eleazar som levde någonstans i Rheinland, ${ }^{7}$ kompilerade sin samling kring år $1325,{ }^{8}$ vari han inkorporerade Jerahme'els verk. Det är inte alltid klart vad i handskriften som är Eleazars verk och vad som är Jerahme' els. Den sistnämnde var ju också i stor utsträckning en kompilator. Vissa fragment är dock "signerade" på följande sätt: "u-māsatī 'anī Yarahma'el ba-sêfer Strbyn (för: Strbwn) ..." - "Och jag, Jerahme'el, fann i Strabos bok..." eller: "u-māsatī 'anī Yarabma'el bo-sêfer Niqola'os mid-Damměseq..." - "Och jag, Jerahme'el, fann i Nikolaos' av Damaskus bok...""

Krönikans gängse titel är, som sagt, given av M. Gaster, medan den hebreiska originaltiteln inte är bevarad. I Krönikans text betecknas verket som Magillat Yarabma'el, eller Malisat Yarabma’el, eller helt enkelt Séfer Yarabmə'eli. ${ }^{10}$ Författarens eller kompilatorns namn återges också $\mathrm{i}$ andra former, som $\mathrm{Ha}$-Yarabmə'eli, och med patronymikon Yarabmə⿳亠口冋 ben Šlomoh. Om Jerahme'el som person vet man praktiskt taget ingenting. Däremot vet man att krönikan inte var hans enda litterära verk. Han skrev också religiösa dikter, piyyutim, och särskilt qadǔsot. ${ }^{11}$ Enligt Abraham b. Azriel, författare till liturgiska kommentarer (I200-t.), författade Jerahme'el även ett, i övrigt okänt, grammatiskt verk, och enligt en 
not i Krönikans handskrift (fol. 377) skrev han om astronomi, även om det inte är säkert att den traktat som följer på fol. 378 är av hans hand. Vidare var han intresserad av matematik och formulerade matematiska gåtor, ${ }^{12}$ samt ägnade sig åt meteorologi, o.d. ${ }^{13}$

Osäkert är både när och var Jerahme'el levde. Man antar dock att det var på Iroo-talet. ${ }^{14}$ A. Neubauer ansåg att han levde i Syditalien på Iooo-talet. ${ }^{15}$ Neubauer bygger sin argumentering på att Jerahme'el verkar ha kunnat inte bara latin, utan även grekiska, vilket framgår av hans användning av latinska källor och citat från grekiska verk, som Josephus', Strabos och Nikolaus' av Damaskus, vilka inte fanns översatta till latin vid denna tid. Jerahme'els kunskaper i grekiska skulle även bekräftas av att en del toponymer i grekisk form förekommer i hans verk, som t.ex. Aśiriyä, Liddi’ah, Qald $\vec{e} a h$, 'Etiopi' ${ }^{2} a h .{ }^{16}$ Så vitt jag kan se är de emellertid latinska och därmed inte bevis för Jerahme' els kunskaper i grekiska. (Vi skall återkomma till de citerade grekiska författarna senare.) Kunskaper i latin ${ }^{17}$ tyder bara på att han levde i Västerlandet, och inte nödvändigtvis i Syditalien. ${ }^{18}$ Enligt S. Baron kan man dra vissa slutsatser från Jerahme'els användning av en apokryfisk text, Pseudo-Philos Liber Antiquitatum Biblicarum: de flesta av dess medeltida handskrifter härstammar från det Heliga Romerska Imperiet, ${ }^{19}$ särskilt norra Italien, vilket skulle tala för att det var där Jerahme'el levde.

Gasters långa titel beskriver Krönikan såsom en samling av apokryfiska och pseudo-epigrafiska skrifter, och man måste medge att denna inte är en krönika i gängse bemärkelse, men eftersom samlingen är ordnad mer eller mindre enligt ordningen av de gammaltestamentliga historiska böckerna, kan den betraktas som ett historiografiskt, krönikeartat verk.

Vi finner här berättelser om världens och människans skapelse, de sju planeterna, Adam och Evas fall, Kain och kainiterna, generationerna från Adam till Noa och efter Noa - här även Berättelsen om Jonites och Nimrod - vidare legender om Abraham, om Josef, exkurser om Roms och Greklands historia, berättelserna om Moses, hans död och himmelsfärd, berättelserna om Nebuchadnezzar, den babylonska fångenskapen, Templets återuppbyggnad och en bok om makkabéerna. ${ }^{20}$ 
Därefter kommer en berättelse om Alexander den Store ${ }^{21}$ och, efter ett hopp på drygt Iooo år, en berättelse om korståg, men dessa två stycken hör antagligen inte till Jerahme'els samling utan till Eliezer ben Ashers. ${ }^{22}$

Förutom Gasters angivelser av Jerahme'els källor har inga ingående studier av dessa gjorts. De två viktigaste källorna är dock säkerställda: Josippon ${ }^{23}$ och Pseudo-Philos latinska Liber Antiquitatum Biblicarum, som i likhet med en del andra judiska pseudoepigrafer bara har bevarats i den kristna traditionen. ${ }^{24}$ En del mindre källor är också kända. Hit hör Kapitel av Rabbi Eliezer (Pirqēe do-Rabbī 'Elīe ezer) 3-I2 (om skapelsen); ett par midrasher, t.ex. om ett barns tillblivelse (Yesirat ha-walad), ${ }^{25}$ om gravslående (Hibbut ha-qebher), ${ }^{26}$ om Gehinnom (Séder Gebinnom), ${ }^{27}$ om Paradiset ( ${ }_{\bar{e}-}$ der Gan ${ }^{`} E$ den), ${ }^{28}$ om änglarna Shemhazai och Azael (f. 2rb); ${ }^{29}$ vidare en Moseskrönika, (f. 37-47) som har paralleller i Den Rättfärdiges bok (Sêfer ha-Yăsar, I200-talet) och en rysk (sic!) version; ${ }^{30}$ de apokryfiska tilläggen till Danielboken: De tre ungdomars sång och Berättelsen om draken, ${ }^{31}$ båda på arameiska. Makkabéerboken, som inte är någon av bibelböckerna med samma titel, är tagen från Josippon. ${ }^{32}$

Här kommer vi att koncentrera vårt intresse till ett stycke rörande Nimrod och Yonites. Den utgör en "apokryf" till Första Moseboken kap. Io, den så kallade Nationernas tavla, som innehåller en genealogi över Noas söner och senare generationer, och där det också talas om Nimrod, Kus' son och Hams sonson (Gen Io:8). Nimrod hade fem bröder, nämnda i vers I0:7, men han själv intar en speciell ställning, då det sägs att han "var den förste som upprättade ett välde på jorden. (9) Han var ock en väldig jägare inför Herren... (Io) Och hans rike hade sin begynnelse i Babel, Erek, Ackad och Kalne i Sinears land," (II) varifrån han drog "till Assyrien och byggde Nineve, Rehobot-Ir och Kela" (12).

Stycket ifråga hör till de fragment som faktiskt finns publicerade. ${ }^{33}$ Det är tillskrivet Strabo och låter så här:

Och jag, Jerahme'el, har funnit i Strabos från Cyprus bok att Nimrod var Sems son, (och) att när Noa var too år gammal 
föddes honom en son, till hans avbild och likhet, och han kallade honom Jonites. Noa, hans far, gav honom gåvor och skickade honom till landet Etan; detta sträcker sig ända till havet Eliochora. Nimrod den onde gick till Jonites att lära sig något av hans visdom, eftersom Guds ande var med denne. Jonites såg $\mathrm{i}$ astrologi(boken) att Nimrod den onde skulle komma till honom för att fă ett råd av honom om hur han skulle kunna bli härskare. Han (dvs. Jonites) började förklara för honom betydelsen av de fyra kungar som Daniel såg. Jonites sade till Nimrod att i början skall assyrierna regera, och de är Sems barn, såsom det är sagt: "Och Sems söner var Elam och Assur... ${ }^{34}$

Sedan, d.v.s. i samma kapitel men efter det publicerade stycket, får vi veta att Nimrod började regera i Babylon, där han fick en son, Bel, som övertog riket efter sin far. Bels son var Ninos, som utökade riket genom att göra sig till härskare även över Assyrien. Där byggde han Nineve och Rehobot, vilket alltså motsäger Genesisbokens uppgift om att det var Nimrod som byggde dessa (och två andra) städer.

Nu uppstår frågan varifrån allt detta kommer. För att identifiera Jerahme’els källor till detta stycke måste man göra en kort översikt över traditionerna rörande de två huvudpersonerna.

I judisk tradition är Nimrod känd som en ond figur. ${ }^{35}$ Detta kan bero på en felaktig etymologi av hans namn. Ursprungligen ett något förvanskat namn på den mesopotamiske guden med det sumeriska namnet Ninurta /Nimurta, ${ }^{36}$ eller (enligt andra forskare) Marduk, har det i hebreiskan associerats med roten MRD 'revoltera'. ${ }^{37}$ Att han, enligt Genesisboken, besatt ett välde förklaras av den övernaturliga styrka som Adams och Evas kläder gav honom. Dem ärvde han från de första föräldrarna genom Methusaleh, Noa, Ham och Kush. I egenskap av härledare för Kushs ättlingar besegrade han jafetiterna. Som nytillträdd härskare bosatte han sig i Sinear, och med utgångspunkt därifrån utökade han sitt välde tills dess att han härskade över hela världen. Samtidigt med att hans makt växte, växte även hans ondska: han tillbad idoler och gjorde allt han kunde för att få sina undersåtar att tillbedja dem 
också. Till sist krävde han att de skulle erkänna honom själv som en gud. Ett av uttrycken för denna hybris var också uppförande av Babels torn i Sinears land, ett alltigenom ogudaktigt verk, och en revolt mot Gud. ${ }^{38}$

Jerahme'els uppgifter om Nimrods rådsökande hos Jonites kan således ha funktionen att fylla en lucka i traditionen. Om Nimrod enligt Genesisboken var grundare till mesopotamiska städer, passar han som Assyriernas förste härskare, vilka, som Jonites förklarade för honom, först av alla skulle inneha herraväldet över världen, allt enligt Daniels profetia.

Jonitesfiguren ter sig något mer svåråtkomlig. Ingenstans i den judiska traditionen finns, mig veterligt, denne Noas fjärde son nämnd. Varken targumerna, midrasherna eller de två viktigaste källorna till Jerahme'els Krönika, Ps.-Philo eller Josippon, som båda har utförliga listor på noakiterna, innehåller någon som helst uppgift om Jonites. Jerahme'els påstående att han har läst om Jonites i Strabo Hak-Kaphtori's bok är, enligt min mening, ett apokryfiskt påhitt. Denna hänvisning använde han redan tidigare i sin krönika, enligt mönster från Josippon, som i sin tur hade tagit över den från Josephus Flavius' Antiquitates Judaicae. Men om dessa fall, i Josephus, i Josippon och på motsvarande ställen i Jerahme'els Krönika verkligen är källhänvisningar, är det i fallet med Nimrod och Jonites bara ett konstgrepp. Strabo, som för övrigt härstammade från Kappadokien (eller Pontos) och inte från Cyprus (hebr. Kaphtor), levde mellan 68 f.Kr. och 20 e.Kr., och är känd huvudsakligen för sin Geografi i I7 böcker, medan hans Historia, som omfattade perioden $\mathrm{I} 46-27 \mathrm{f}$.Kr. inte har bevarats. Man vet dock att den var en Zeitgeschichte (samtida historieverk) och som sådan torde den inte ha kunnat innehålla uppgifter om sådana i tiden avlägsna figurer som Jonites eller Nimrod.

Detta leder oss till att anta att Jerahme'el försöker dölja den rätta källan. Och om en judisk historiker döljer sina källor, kan man misstänka att det rör sig om kristna sådana. Vi har redan påpekat att Jerahme'els Krönika innehöll fragment av Pseudo-Philos Liber Antiquitatum Biblicarum. Den tog han från kristet håll, och dess text återöversatte han från latin till hebreiska. ${ }^{39}$ Man vet att vissa 
verk ur den judiska apolkryfiska (mer tekniskt kallad pseudoepigrafiska) litteraturen ofta traderades inom kristna kretsar, och ibland "återkom" de till den judiska kultursfären först, om någonsin, under medeltiden (exempelvis genom Josippon).

$\mathrm{Nu}$ är det så att man faktiskt känner till ursprunget till Jonitesgestalten, ${ }^{40}$ eller åtminstone den text där den är belagd för första gången. Det är Skatternas grotta, ${ }^{41}$ en syrisk apokryf som i sin idag kända form härstammar från 50o-talet, fast man räknar med att kärnan i texten är två århundraden äldre. Här finner vi faktiskt både Jonites eller Jonton, som hans namn är här, och Nimrod.

Vi făr veta att Nimrod föll en gång framför elden som kom ner från himmelen, och detta blev upprinnelsen till persernas vördnad för elden ${ }^{42}$. Därefter begav sig Nimrod till landet Nod för att där vid havet Arkos (eller Bros) ${ }^{43}$ träffa Yōnātōon ${ }^{44}$ (eller Jon(i)ton). Denne lärde honom under tre år visdomen och innehållet $\mathrm{i}$ uppenbarelseskrifter. Nimrods lärdom, får vi veta, kallas av perser "uppenbarelse" (syr. gelya $\bar{a} \bar{a}$ ) och av romarna "astronomi", men är inget annat än astrologi, en "demonernas fel(syssla)", som magerna ägnar sig åt.

Men Skatternas grotta har aldrig översatts till vare sig hebreiska, grekiska eller latin, i vilka eventuella versioner Yerahme'el rent teoretiskt skulle ha kunnat finna Jonitesgestalten. Det finns emellertid en annan syrisk text som, så att säga, tog över denna figur. ${ }^{45}$ Denna text är Pseudo-Metodios'Apokalyps, skriven vid slutet av 600-talet. ${ }^{46}$

Här sägs det att när Noa var 700 år gammal föddes honom en son, Jonton (Yōnțōn), "till hans avbild och likhet", och när denne var 200 år gammal gav Noa honom gåvor och skickade honom till Öst. Så kom han till ett land kallat 'Solens eld' (nūrr šemš̄a), eller snarare 'Solens land' (kürr šemšăa), ${ }^{47}$ där solen stiger. Jonton fick visdomsuppenbarelser och började som den förste på jorden använda stjärnornas banor, alltså astrologin, för att sia. När Nimrod kom till honom fick han från honom i uppdrag (sic!) att bli kung (maqabbel puqdāne do-nehwē malkāa, 5,2). När Babel byggdes blev Nimrod dess konung. ${ }^{48}$ Fred rådde mellan Nimrods och Jontons kungariken. Den senare skickade även ett brev till Nimrod $\mathrm{i}$ vilket han förutspådde ett krig mellan semiter och hamiter, ur vilket Nimrod skulle gå som segrare. ${ }^{49}$ 
Såsom varande en av de första anti-muslimska skrifterna, rönte Apokalypsen oerhörd popularitet, både bland syrianer och snart även andra kristna, vilket man kan förstå från det att den mycket tidigt, i början av 700-talet, blev översatt till grekiska, ${ }^{50}$ och snart därefter till latin. ${ }^{51}$ Det finns latinska handskrifter med Ps.-Metodios’ verk från 700-talet, medan de grekiska är relativt sena (I300-t.). I de flesta grekiska textrecensioner som publicerats (det finns fyra!)

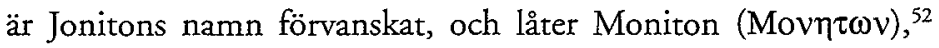
och så heter han också i den armeniska traditionen (uppenbarligen baserad på den grekiska ${ }^{53}$ ). I den latinska, som håller sig nära den syriska texten, heter han Ionitus. Detta betyder dock inte att den latinska versionen var en direkt översättning från syriska. Den översattes säkerligen från grekiska, vilket bl.a. syns i namnet på det hav i Öster vid vilket Ionitus' land låg, nämligen "Hiliu Chora, id est Regio Solis", en klar kopia av det grekiska iं $\lambda$ íov $\chi \omega ́ \rho \alpha,{ }^{54}$ som i sin tur återger det hypotetiska syr. küur šemšă, med samma betydelse.

Men läste då Jerahme’ el den grekiska eller latinska versionen av Pseudo Metodios' Apokalyps? Vi måste kontrollera om det inte föreligger något mellanled mellan honom och Apokalypsen.

A priori finns det två sådana som Jerahme'el skulle kunna ha använt. Vi har redan påpekat att Jerahme'el hade en del naturvetenskapliga intressen, bl.a. astronomi. Man kan då inte utesluta att han hade tillgång till den latinska s.k. Nimrodboken (Liber Nemrod)..$^{55}$ Trots titeln, som antyder att det kan röra sig om en apokryf, är det en medeltida mytologisk handbok i astronomi. ${ }^{56}$ Verket, som skrevs vid slutet av 700-eller början av 800-talet, innehåller i sina tre delar en allmän presentation av universum, en beskrivning av solsystemet, och en beskrivning av månens rörelser samt meteorologiska frågor. Man ansåg tidigare att Nimrodboken hade direkta orientaliska, närmare bestämt syriska, källor, inte bara därför att Jonitesgestalten omnämns där, utan också därför att det finns en referens till att året börjar den I:a oktober. ${ }^{57}$ Men mer sannolikt är att dess författare baserade sitt verk på latinska texter och västliga traditioner, bland vilka nämns de Pseudo-klementinska skrifterna,

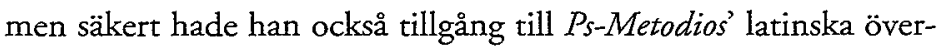
sättning. ${ }^{58}$ 
I Nimrodboken möter vi som sagt Nimrod och Joniton (här under namnet Joanton) igen, vilka diskuterar astronomiska spörsmål. Men förhållandet dem emellan är omvänt: det är Nimrod som är läraren, medan Joanton är eleven, och i så fall måste Nimrodboken avskrivas som potentiell källa för Jerahme'el.

Det finns emellertid ytterligare ett möjligt mellanled, nämligen ett medeltida latinskt verk, Historia scholastica av Petrus Comestor (eller Manducator; fr. Pierre Mangeur).

Petrus Comestor, född och uppruxen i Troyes, blev senare dekanus i katedralen där, och Iı64-68 kansler för katedralskolan i Paris, innan han drog sig tillbaka till St. Victorklostret i samma stad (han dog II79). Han var för sin samtid känd som en stor bibelkännare och kommentator. Hans Historia scholastica var en universiell krönika för perioden från skapelsen fram till den nytestamentliga epoken. ${ }^{59}$ Under medeltiden var detta en mycket populär skrift, erkänd av både påven och Parisuniversitetet att användas i teologiundervisningen, vilket förskattade författaren titeln Magister historiarum. ${ }^{60}$ Även Petrus kände Ps-Metodios' Apokalyps, och Jonitonoch Nimrod-traditionen finns med här, och till yttermera visso i en form som är nära både Apokalypsen och Jerahme'els Krönika. Det är däremot säkert att Petrus Comestor hade använt en annan handskrift än de som är kända från de två editioner av Apokalypsen som finns (Sackur 1898, Kortekaas 1998). Den publicerade latinska texten låter:

Ionitus autem, filius Noe, introivit in Eoam usque ad mare, qui vocatur "Hiliu Chora", id est "Regio Solis", in quo solis ortum fit.. - "Ionitus kom således till Eoam ända fram till havet som kallas Hiliu chora, det vill säga Solens Rike, där solen stiger..."61

men i Historia Scholastica finner man:

... dedit Noe donationes filio suo Ionitho, et dimisit eum in terram Ethan, et intravit eam Ionithus usque ad mare orientis, quod dicitur Elioschora, id est solis regio.... - "Noa gav sin son Ionitus gåvor och skickade honom till landet Ethan, och han kom in i det ända till östhavet som kallas Elioschora, det vill säga Solens Rike..." ${ }^{\text {2 }}$ 
Jämför man nu den form av toponymen som förekommer i Jerahme'els Krönika ('YTN = Eitan) med dem som finns i den latinska översättningen av Pseudo-Metodios' Apokalyps (Eoam) och Petrus Comestors Historia Scholastica (Ethan), måste man konstatera att den ligger närmare den senares form. Det skulle således betyda att Jerahme'el tog sin Jonitespassus från Peter Comestors verk, och inte direkt från Apokalypsen. Man måste emellertid notera att Comestors toponymer ju också måste komma från Ps.-Metodios' Apokalyps, dock från en annan och bättre handskrift (med den korrekta formen Ethan) än den äldsta som har bevarats, och som vi känner från den moderna utgåvan. ${ }^{63}$

Icke desto mindre tycks det mer sannolikt att Jerahme'el kände Jonites från Comestors Historia. För det första finns det spår av Comestors verk i andra stycken av Jerahme'els Krönika, ${ }^{64}$ några som dock måste undersökas separat. Man kan även framföra ett annat argument. Petrus fick sin utbildning i katedralskolan i Troyes, och där utvecklade han även intresse för den judiska exegetiken. Vid arbetet på sitt verk använde han en del - antagligen muntliga - judiska källor. ${ }^{65}$ Detta var inte något undantag, ty idén om hebraica veritas var ju känd inte bara på Hieronymus' tid. ${ }^{66} \mathrm{I}$ Troyes fanns det samtidigt en berömd rabbinsk skola under Rashi (dog IIO5) och hans efterträdare Samuel ben Meir (Rashbam, d. I174). Om kristna teologer, som t.ex. Hugo från Sankt Viktorklostret (d. II4I), på IIOO-talet där kunde konsultera judiska exegeter, är det inte osannolikt att en del kristet material i samma intellektuella miljö i Troyes, eller i någon annan stad i norra Frankrike, på ett eller annat sätt kunde hamna i judiska händer, och i så fall så småningom även i Jerahme’els.

Detta leder till ytterligare två hypotetiska slutsatser. Om Jerahme'el kände Comestors (d. II79) verk skrivet i mitten på Iıoo-talet, kunde han inte leva på Iooo-talet (som Ad. Neugebauer antog), utan tidigast i mitten av, eller snarare under andra hälften av rrootalet. Det är också sannolikt att hans hemstad inte låg i Norra Italien (vilket Salo Baron trodde), utan i norra Frankrike där kontakterna mellan de judiska och kristna exegeterna är belagda. 


\section{Appendix}

Latinsk text av de relevanta fragmenten ur Petrus Comestors Historia Scholastica, enl. Patrologia Latina, vol. I98, Paris 1855, col. 1088 (modern kritisk utgåva saknas).

Iam in trium milium annorum, postquam exivit Noe de arca aedificaverunt filii Noe novam possessionem in exteriora terra et apellaverunt nomen regionis illius Thamnon secundum nuncupationem numeri, qui exierunt de archa, id est VIII. C. autem anno de terciam chiliadam natus est Noe filius secundum ipsius similitudinem et vocavit nomen eius Ionitum. CCCmo vero tempore de trium milium annorum dedit Noe donationes filio suo Ionito et demisit eum in terram Eoam et post obitum Noe DC et XC anno in eosdem trium milium annorum ascenderunt filii Noe de terra Eoam et aedificaverunt sibi turrem in terra Sennahar, et illuc divise sunt linguae et disperse sunt super faciem totius terrae. Ionitus autem, filius Noe, introivit in Eoam usque ad mare, qui vocatur hiliu chora, id est regio solis, in quo solis ortum fit et habitavit ibidem. Ionitus accipit a Deo donum sapientiae, qui non molum hoc tantum, sed et omnem astronomiae articulum factusque inventor. Ad hunc discendens Nebroth qui fuit gigans et eruditus ab eo accipit ab illo consilium, in quibus regnare coepissent. Hi autem Nebroth ex filiis discendebat hiroum; qui fuit filius Sem et ipse primus regnavit super terram.

\section{Noter}

I. Sêfer Yosifon (Yosippon), ed. D. Flusser, I-II, Jerušalayim 1978-80.

2. A. Graboïs har inte med den i sin förteckning över hebreiska medeltida krönikor: Les sources hébrä̈ques médiévales, vol. I: Chroniques, lettres et responsa, (Typologie des sources du Moyen Âge occidental, fasc. 5o), Turnhout I987, s. 89-9I.

3. The Chronicles of Jerahmeel ..., translated for the first time from an unique manuscript in the Bodleian Library by $M$. Gaster, together with an introduction, critical notes, a full index, and five facsimiles, (Oriental Trans- 
lation Fund: new series, 4), London 1899, repr.: New York 197x. Här tar vi oss friheten att ändra Gasters titel till singular.

4. A. Neubauer \& A.E. Cowley, Catalogue of the Hebrew manuscripts in the Bodleian Library, vol. II, Oxford 1906, p. 208-215 (cat. number 2797-Ms. Heb. d. II). Handskriften köptes från Dr R.N. Rabinowitz' samling i München, år 1887 .

5. Gasters översättning, s. I (Compiler's Preface).

6. Gasters översättning, s. 2.

7. Detta framgår från de tyska dialektala former av veckodagsnamn som han använder.

8. Medieval Jewish Chronicles and Chronological Notes, ed. from printed books and manuscripts by A. Neubauer, vol. I, Oxford I887, s. xx; \& idem, 'Yerahmeel ben Shelomoh', Jewish Quarterly Review II (1898-99), s. 364 (364386).

9. A. Neubauer, 'Yerahmeel Ben Shelomoh', Jewish Quarterly Review Ix (I898-99), s. 367 .

10. J. Dan, 'Jerahmeel ben Solomon', Encyclopdedia Judaica, vol. 9 (1971), col. 1345 .

II. Som beskriver den skapade världen och änglarnas helighet; J. Dan, ibid. Urval av hans dikter i: Neubauer, 'Yerahmeel ...', s. 369-386; se även S.J. Halberstam, 'Notes to the J.Q.R., XI, pp. 364-386', Jewish Quarterly Review II (I898-99), s. 697ff.

12. Två handskrifter i Bodleian Library innehåller matematiska gåtor. Ett urval publicerades av Neubauer, 'Yerahmeel ...'.

13. Enligt S.W. Baron (A Social and Religious History of the Jews, vol. 6: Laws, Homilies and the Bible, 2nd ed., New York I958, s. 422, n. 56) kom Jerahme'els kunskaper $\mathrm{i}$ astronomi samt hans intresse för vetenskaplig interpretering av antika traditionerna sannolikt från hans vistelser $\mathrm{i}$ sådana kulturcentra som Rom och Lucca (snarare än i Tyskland).

14. Enligt J. Dan, op. cit. (se not Io), dock utan någon argumentering.

15. Neubauer, 'Yeraḥmeel ..., s. $366 f$.

16. Citerade av Neubauer, op. cit., s. 367; angivna även i Gasters översättning, s. $68 \mathrm{f}$.

17. The Hebrew Fragments of Pseudo-Philo's Liber Antiquitatum Biblicarum preserved in the Chronicles of Jerahmeel, ed. \& transl. by D.J. Harrington, (Texts and Translations 3: Pseudepigrapha Series, 3), Missoula, Montana 1974, introd.

I8. Syditalien antas vara Josippons författares hemland.

19. S.W. Baron, op. cit. (n. I3), p. 422, n. 56: Jerahme'els intresse, större än Josippons, att synkronisera den romerska historien med den judiska pekar också på att hans hemort var någonstans inom det Heliga Romerska Imperiet.

2o. Med denna avslutas Gasters översättning.

2I. Denna version, olika Pseudo-Kallisthenes' och Historia de Prelizs, är översatt på basis av vår handskrift av M. Gaster, 'An Old Hebrew Romance of. Alexander, translated from Hebrew MSS of the twelfth century', The Journal of 
the Royal Asiatic Society of Great Britain and Ireland 1897 , s. 485-549; se även W.J. van Bekkum, 'Alexander the Great in Medieval Hebrew Literature', Journal of the Warburg and Courtauld Institutes 49 (1986), s. 233 f.

22. M. Waxman, $A$ bistory of Jewish literature from the close of the Bible to our days, $I$, 2nd ed. New York 1938 , s. 527; de stycken från Josippon som avbryter Jerahme'els text kommer också från Eliezer, Waxman, $i$ bid.

23. J. Reiner, 'The original Hebrew Yosippon in the Chronicle of Jerahmeel', Jewish Quarterly Review 60 (I969-70), s. I28-146. Citat från Josippon är dels Jerahme'els dels Eleazar ben Ashers, som på egen hand kompletterade de stycken som Jerahme'el kopierat; Reiner, op. cit., s. $138 f$.

24. Pseudo-Philon, Les anitquités bibliques, éd. D.J. Harrington, trad. J. Cazeaux, comm. Ch. Perrot \& P.-M. Bogaert, t. I-II, (Sources chrétiennes 229-230), Paris 1976; (latinsk text med synoptisk fransk översättning); L. Cohn och D.J. Harrington har på ett övertygande sätt visat att Gasters påstående om att Jerahme'el hade den ursprungliga hebreiska texten, är felaktig. Jerahme'els text är nämligen en retro-översätıning från latin; L. Cohn, 'Pseudo-Philo und Jerachmeel', [i:] Festschrift zum siebzigsten Geburtstage Jakob Guttmanns, (Schriften hrsg. v. der Gesellschaft zur Förderung der Wissenschaft des Judentums), Leipzig I915, s. I73-185; The Hebrew Fragments of Pseudo-Philo... (n. 17 ).

25. Bet ha-Midrasch: Sammlung kleiner Midraschim und vermischter Abhandlungen aus der ältern jüdischen Literatur, hrsg. v. A. Jellinek, I, Leipzig I853, s. 153-158; Ozar Midrashim: a library of two bundred minor midrashim, ed. by J.D. Eisenstein, I, New York 19I5, s. 243-244.

26. Bet, I, s. I50-152; Ozar, I, s. 93-94.

27. Bet, I, s. 147-I49; Ozar, I, s. 9I-92.

28. Bet, III, (1856), s. I3I-I40; Ozar, I, s. 85-89.

29. Bet, IV (I857), s. I27-I28; Ozar, II (I9I5), s. 549-550.

30. E. Turdeanu, 'La "Chronique de Moïse" en russe', Revue des études slaves 46 (I967), s. 35-64; omtryckt i idem, Apocryphes slaves et roumains de l'Ancien Testament, (Studia in Veteris Testamenti pseudepigrapha 5), Leiden I98I, s. 277-305.

3I. M. Gaster, 'The unknown Aramaic original of Theodotions additions to the Book of Daniel', Proceedings of the Society of Biblical Archaeology, Nov.Dec. 1894 - Jan.-Febr. I895; omtryckt i: M. Gaster, Studies and Texts in Folklore, Magic, Medieval Romance, Hebrew Apocrypha and Samaritan Archaeology, London, I (1925-28), s. 39-68 \& 3 (I925-28), I6-2I.

32. Gaster's text slutar med Judas Makkabeus, men andra avsnitt av samma handskrift, som kanske också är delar i Jerahme'els Krönika, fortsätter berättelsen till Jerusalems fall och kanske ännu längre, till Mishnas författande i 2 årh. e.K.

33. A. Neubauer, op. cit., s. 367.

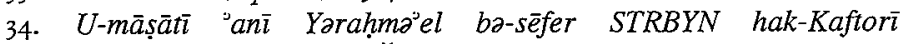
[HKPWTWRY] kī Nimrod ben Šem hāyāh kī ka-'ašer hāyāh Noah ben mesath šānāh nōladh lō ben ba-dhmuthō [BMDMWTW] u-bh-șalmō wa- 
yiqra' 'eth šamō Yonites [YWNYTS, delvis vokaliserat]. Wa-yyitten lō Noah "abhiw mattānoth wa-yišslah "ōthō ba-'ares 'YTN wa-ya'ahaz beh cad yam ${ }^{\circ} E l i^{\circ} \bar{o} k h \bar{o} r a$ ['LY'WKWR', delvis vokaliserat]. Way-yēlekh Nimrod har-rēesac 'el Yonites lilmōdh me-hākhmōthayw kī ruah 'Elōhīm ba-qarbō. Way-yēre' Yonites ba-"aytrologiyah [for: "astrologiyah] $k \bar{\imath}$ ba $\bar{a}^{\circ}$ elayw Nimrod har-

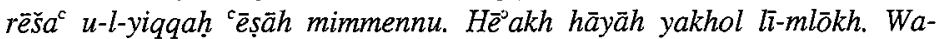

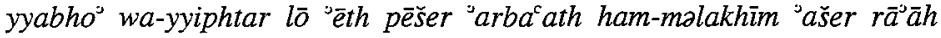

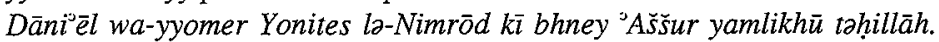

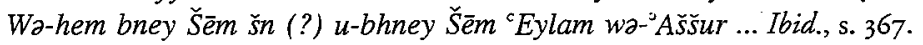

35. Bereshit Rabba, 38, 9 \& passim. (L. Ginzberg, 'Die Haggada bei den Kirchenvätern und in der apokryphischen Litteratur', Monatsschrift für die Geschichte und Wissenschaft des Judentums 43 (1899), s. 466); det finns dock en annan tradition (i Targum Ps-Jonathan (ad Gen. IO, II) enligt vilken Nimrod drog sig tillbaka ovillig att ha något att göra med bygget av Babelns torn; Targum Pseudo-Jonathan: Genesis, transl., with introd. and notes by M. Maher, (The Aramaic Bible IB), Collegeville, MN r992, p. 47f.

36. Enligt E.A. Speiser ('In search of Nimrod', Eretz Israel 5 (I958), s. 3236) ligger till grund för Nimrodgestalten en mesopotamisk härskare vars namn innehöll Ninurta- eller Marduk-leden, t.ex. Tukulti-Ninurta I. Det är sannolikt att det rör sig om en slags kompositfigur personifierande Mesopotamien i băde politisk och kulturell mening; P. Machinist, 'Nimrod', [i:] The Anchor Bible Dictionary, ed. D.N. Freedman, vol. 4, New York 1992, kol. III6-III9.

37. Hebr. nimrod - 'vi skall revoltera' Targum Pseudo-Jonathan Io,8f upprepar 3 gånger ordet 'rebell'. Jfr dock n. 35 .

38. L. Ginzberg, The Legends of the Jews, I: Bible times and characters from the creation to Jacob, Philadelphia 1942, s. 177-179. Traditioner om Nimrods förehavanden med Abraham är här ovidkommande.

39. L. Cohn, op. cit. (n. 24), s. I73-185; D.J. Harrington, op. cit. (n. I7), s. I-7.

40. S. Gero [Gerö], 'The legend of the fourth son of Noah', Harvard Theological Review 73 (1980), s. 321-330.

4I. La caverne des trésors: les deux recensions syriaques, éd. ( $8 \mathrm{~T}$ trad.) par Su-Min Ri, (Corpus Scriptorum Christianorum Orientalium 486-487, Scriptores Syri 207-208), Lovanii 1987.

42. : Kap. 27 enl. Su-Min Ris uppdelning, s. 80-83.

43. Havets namn varierar starkt i olika handskrifter; se Su-Min Ri, syr. text s. 2Iof, not 7:2.

44. Namnet vokaliserat i den östsyriska versionen, Ris utg. s. 2IO, v. 8; i den västsyriska versionen stavas hans namn Ywn(y)twn.

45. Cp. W. Witakowski, 'The Division of the Earth between the Descendants of Noah in Syriac Tradition', Aram Periodical 5 (1993, tryckt 1996) (=A Festschrift for Dr. Sebastian P. Brock), s. 635-656.

46. Die syrische Apokalypse des Pseudo-Methodius, hrsg. (\& übers.) v. G.J. Reinink, (CSCO 540-54I, SS 220-221), Louvain 1993.

47. Med tanke på de grekiska och latinska formerna (se nedan) borde man nog emendera det syriska $n \bar{u} r$ šemšă till kūr šemšă; Reinink, övers. 6, n. 4:I. I den syriska skriften är skillnaden mellan 'k' och 'n' minimal. 
48. Vidare sägs det ang. Joniton att jafetiterna skickade till honom sina arkitekter som byggde en stad som kallats Joniton.

49. I judisk tradition kämpade Nemrod som kuschiternas härskare segerrikt mot jafetiterna.

50. Den grekiska översättningen föreligger $i$ ett par versioner, varav några (så kallade 'långa') interpolerades på 8oo-talet; W.J. Aerts, 'Zu einer neuen Ausgabe der "Revelationes" des Pseudo-Methodius (syrisch-griechisch-lateinisch)', [i:] XXIV. Deutscher Orientalistentag ... 1988 in Köln: ausgewäblte Vorträge, hrsg. v. W. Diem u. A. Falaturi, (ZDMG Supplement 8), Stuttgart 1990, s. 123-130.

5I. Den latinska texten publicerades på basis av fyra handskrifter från 700-talet: Die Apokalypse des Pseudo-Methodius: die ältesten griechischen und lateinischen Übersetzungen, hrsg. von W.J. Aerts und G.A.A. Kortekaas, vol. III, (Corpus SCO 569-57., Subsidia 97-98), Lovanii 1998; en äldre utgåva: E. Sackur, Sibyllinische Texte und Forschungen: Pseudomethodius, Adso und die Tiburtinische Sibylle, Halle a.S. 1898 , s. 59-96, introd. s. 3-58.

52. Die Apokalypse des Ps.-Methodios, hrsg. v. A. Lolos, (Beiträge zur klassischen Philologie 83), Meisenheim am Glan 1976, s. 56; Die dritte und vierte Redaktion des Ps.-Methodios, [hrsg. v.] A. Lolos, (Beiträge zur klassischen Philologie 94), Meisenheim am Glan 1978, s. 28; Aerts' och Kortekaas' utg. p. 82 (not $[3], 4,1)$.

53. I den armeniska översättningen av Mikael Syrierns Krönika; Sackur, op. cit., s. 15 .

54. Aerts' och Kortekaas' utg. (se not $5 \mathrm{r}$ ), $\$[3], 4$, s. 83 (lat.) och 82 (grek.).

55. S.J. Livesey \& R.H. Rouse, 'Nimrod the Astronomer', Traditio 37 (I98I), s. 203-266.

56. Att associera Nimrod med astronomi i den västliga traditionen har sina rötter i Recognitiones av Ps.-Clemens Romanus, Livesey \& Rouse, op. cit., s. $2 \mathrm{II}-2 \mathrm{I} 3$.

57. Livesey \& Rouse, op. cit., s. 208.

58. Ibid.

59. En modern utgåva saknas. J.P. Migne's utgåva, den enda tillgängliga, baseras på ett tryck från '1600-talet: Petrus Comestor, 'Historia Scholastica', Patrologia Latina vol. 198, Paris 1855, col. I049-1722.

6o. S.R. Daly, 'Peter Comestor: Master of Histories', Speculum 32 (I957), s. $62-73$.

61. Sackur, op. cit., s. 63f; i Kortekaas' utg. (s. 83): 'Jonetus'.

62. Comestor, Patrologia Latina, vol. 198, col. 1088.

63. Och från äldre utgåva av Sackur.

64. Se anmärkningar i Gasters introduktion.

65. E. Shereshevsky, 'Hebrew tradition in Peter Cometsor's Historia scholastica', Jewish Quarterly Review 59 (I969), p. 268-289; S. R. Karp, Peter Comestor's Historia Scholastica: a study in the development of literal scriptural exegesis, (Diss., Tulane University 1978), Ann Arbor: University Microfilms International 1980, p. 197-217.

66. A. Grabois, 'The Hebraica veritas and Jewish-Christian intellectual relations in the twelfth century', Speculum 5o (1975), p. 613-634. 